\section{Equity and the goal of Health for All ${ }^{1}$}

\author{
George A. O. Alleyne
}

"It is theoretically possible to have a society in which the inequalities are great but the average health is good. In reality, however, where there are the greatest inequalities in health, the average health of the population is poor."
Speech presented in Caracas, Venezuela, 15 February 2002 as part of the events in that country launching the celebration of the Centennial of the Pan American Health Organization.
First let me thank you not only for the opportunity to address you here in Venezuela but also for having given me the opportunity to reflect again more seriously on the concept of equity as it applies to what we do. I hope to show you how the concept of equity is embedded in the vision of Health for All, and the relevance of both to the struggles of the countries of the Americas for a better life for all their citizens. This is the centennial of the Pan American Health Organization (PAHO), and it is fitting that those of us who serve the Organization take time to reflect on some of the essential values that underpin what we do. I believe that this has been a forte of my predecessors throughout the years as they must have believed, as I do, that no organization can survive and flourish unless it has some bright vision of what might be and the way to get there. I believe that the noble vision of Health for All, explicitly or implicitly, must have guided what we have done and what we are.

When I was a medical student, we were taught that the social and physical environment had an effect on the development and progress of disease, and one could see obvious examples of that almost every day. But the focus was predominantly on the individual. As I became a practicing internist my concern was still mainly, if not exclusively, for the health and well-being of my individual patient, and I believe that that is the proper focus of those engaged in personal-care medicine. Success was measured in terms of the outcome of treatment I had prescribed or to the extent I could have him or her protected against some risk to health. I have to confess that from time to time as I saw patients come for treatment late in the course of their disease or saw their disease affected by conditions of deprivation that were not of their own making, I could not help but reflect on the apparent social injustice that made some healthy and others not.

Later I became much more aware of the call of population medicine, or rather population health. Perhaps that is one of the reasons for my joining the Pan American Health Organization 20 years ago. There is a basic difference between the causes of disease in patients and the incidence of disease in populations. We know that cigarette smoking causes cancer of the lung. If everyone in a population smoked, some would develop cancer, but we would never be able to identify tobacco as an etiologic factor. However, if one is seeking to enhance the health of populations, which is the main focus 
of public health, one has to be concerned with the distribution of the problems and the factors that influence such distribution in those populations. In the late 1970s the countries of the Caribbean, where I come from, were very advanced in their thinking about the steps to be taken to deal with population health issues, and they actually elaborated concepts that were very similar to those that subsequently were included under the heading of "primary health care."

I found later that the Caribbean countries were not alone and that there was considerable ferment in public health circles in Latin America about the social causes of disease and the link between health and the various measures to achieve social progress. Health figured in the Pan American efforts to build a better future for the Americas. It could not have come as much of a surprise to the health authorities of this part of the world when the 30th World Health Assembly of the World Health Organization (WHO), in 1977, called for social justice and set Health for All as a goal. It is no accident that the main proponent and advocate of Health for All, Halfdan Mahler, of Denmark, was a man with a strong social conscience and was a firm believer in the possibility of galvanizing the world's nations to see the indecency of the differences in health that existed within and between nations. That World Health Assembly enthusiastically recommended that governments strive for "the attainment by all citizens of the world by the year 2000 of a level of health that will permit them to lead a socially and economically productive life." The famous Declaration of Alma-Ata, made in 1978 at a joint conference of the World Health Organization and the United Nations Children's Fund, stated that:

\section{The existing gross inequality in the health status of the people, particularly between developed and developing countries as well as within countries, is politically, socially and economically unacceptable and is therefore of common concern.}

The elaboration of the strategy of primary health care, on which the success of Health for All was to depend, pointed out the importance of the application of appropriate technology, community participation, and intersectorial cooperation. It is impressive to note in retrospect that ministers of health were proposing a goal that they must have known was beyond their capacity to achieve by themselves. Such a goal would have to involve all sectors of the State, and I must admire their confidence in thinking that they would be able to mobilize those other sectors for the good of health.

Of course there were doubters and skeptics who took the call literally and as basis for a timebound program, rather than an enunciation of the aspiration that the world as a whole would see the need to attend to the health of all the world. Health for All had to be seen as a work continuously in progress and not as one simplistically defined target with the year 2000 as the time when the history of medical progress would end, although progress could be defined and measured in terms of specific intermediate targets. Subsequent analysis of what the concept meant usually turned around the need to enshrine three basic ideas or approaches. The first is the rights approach, which casts health in the guise of a human right. The second involves the concept of ethics, especially as applied to population groups and less to the individual. The third, which is the most relevant to us here, is the notion of equity, conceived as fairness. I am convinced that the basic thesis and these approaches remain as valid today as when they were enunciated 25 years ago.

The rights approach has gained even more prominence with the flourishing of the call for observance of social, cultural, and economic rights and the inclusion of many aspirations under the umbrella of human rights. It has often been proposed that these rights have the same dimension as the more traditional civil and political rights. I have sometimes had difficulty in understanding clearly the nature of the right to health when health as a state of being is included among social rights, and I believe that health, unlike civil rights, cannot be "justifiable." No one can guarantee the right to health in the same way there can be a guarantee for the right to liberty of person or the right of association. In my view the most appropriate formulation of the right to health is in the words of the American Declaration of the Rights and Duties of Man, which was adopted by the Ninth International Conference of American States, in Bogotá, Colombia, in 1948. In addition to recognizing the "right to life, liberty and the security of person," that Declaration states: "Every person has the right to the preservation of his health through sanitary and social measures relating to food, clothing, housing and medical care, to the extent permitted by public and community resources." These measures can be more clearly recognized as being justifiable, and some entity such as the State can theoretically be held responsible for their provision. To quote the distinguished ethicist Daniel Callahan, "An undisciplined use of the rhetoric of rights can water down the concept of rights, bleaching out its full force."

The concept of the ethics of health has had a major transformation as the goal of Health for All has been considered more in depth. In a seminal publication on ethics, equity, and Health for All, Daniel Wikler articulated the four stages through which bioethics passed, although it must not be as- 
sumed that one stage supplants the next. In the first stage, the emphasis was more on medical deontology and the fashioning of a code of professional interaction between doctors and patients. The discourse was between professionals. The second stage saw the debate and discourse extend to include the civil society, which was taking a keen interest in the behaviors of professionals. The third stage represented the incursion of ethical thinking into areas such as the appropriate allocation of health resources. The fourth stage, which is perhaps more directly related to Health for All, is the moreupstream application of ethical principals in considering the determinants of health and how they are distributed and applied. Respect for individual choice and the principle of personal autonomy were and are still important. But the broadening of the field to consider the needs of populations and the embracing of issues, such as the allocation of resources to populations to ensure the necessary sanitary and social measures, is a major step forward. I believe the broadening of the field was not dissociated from the interest generated by the movement for Health for All. I view the current ethical debates on the critical questions about the nature and sanctity of life as of fundamental importance, but not in the stream of the ethics that has to do with the issues surrounding population health concerns.

One cannot easily separate the issue of equity from that of ethics. In a very real sense the concept of equity in health implies some of the moral judgments that are the essence of ethical thinking on population health. There has been an explosion of interest in the concept of equity as applied to health in the past 20 years. There is now general agreement that in its most basic sense that inequity in health represents inequalities that are unfair and unjust. I have to admit that these two concepts of fairness and justice evoke many different interpretations in different settings.

Most of you are aware of the utilitarian philosophy that derives mainly from the thinking of Bentham and Mill. Most young physicians have the natural tendency to be utilitarians. I was one myself when I was young, and the essential concept is that one should maximize good health outcomes. In this sense, the important thing was the health of the average population. This is in theory not too distant from, and perhaps a derivative of, the Hippocratic tradition in which the physician sought to do good for the individual patient. There was no or little concern for the weaker vessels; there was little appreciation of the differences between the weak and the strong, provided the average level was raised. In public health we became fixed on averages, and to some extent we still are. We measure health status by the averages of indicators of mortality and morbidity.
One thing that Health for All did was to force thinking on what was meant by "All." Health for All implied that there would be distributive justice and that there would be some minimum state of health to which all would aspire, and that there would be some entity responsible for ensuring the achievement of that state. Equity, as applied to health, was seen as more in line with the egalitarian approach, and I confess to my bias in this direction. Most persons who have heard of the notion of equity in health have heard it referred to as the state in which there are no unfair inequalities. In other words, inequity represents the existence of differences in health between people or populations that are avoidable, are not volitional, and the correction of which can be laid at the door of some agent. It would appear at first blush that there is a major difference in both conceptual and policy terms between the utilitarian or aggregative approach and the egalitarian or more distributive approach. Indeed, Health for All was promoted mainly in terms correcting the distributive injustice that is widespread around the globe. But in practice the differences may be narrow. It is theoretically possible to have a society in which the inequalities are great but the average health is good. In reality, however, where there are the greatest inequalities in health, the average health of the population is poor. As Amartya Sen, winner of the 1998 Nobel Prize in Economics, puts it: "Aggregate health is often best advanced by concentrating on the poorest, since this is where there is more scope for gaining further ground; but that very policy will have the effect of reducing distributive inequality as well. Thus, the alleged tension between the two objectives may be far weaker than is often presumed."

More recent thinking by philosophers such as Norman Daniels has explored the issue further. Their work has made it clear that it is not enough to describe distributive injustice in relation to health outcomes. Rather, it is critical to examine the determinants of health that, due to their unequal distribution, contribute to inequities in health. Thus, Health for All must include correction of the unequal distribution of those determinants.

There has to be appreciation at the political level of the different approaches to making Health for All a reality. There is no doubt that the strictly egalitarian approach may not be the most efficient, and this has serious implications for us in the Americas. Attempts to raise the level of health of the sickest or the most disadvantaged may not be the best use of resources in all societies.

The Region of the Americas has the unfortunate reputation of being the area of the world in which there is the most social inequality. There is a wide and widening gap between the rich and the 
poor, and the apparently inevitable liberal democratic approach to societal organization favors the widening of this gap. There are concomitantly gross differences in health outcomes between social groups in the Americas. While social stratification is manifest in health differences in all societies and in all strata of society, it appears that the gaps are wider in the Americas than elsewhere. It has been customary to attribute differences in health status to this social inequality, and there have been several studies showing that the differences in health status among countries could be attributed in part to the maldistribution of income, for example. This view is now being questioned with more and better data. Even if the inequality in income is mirrored by inequality in health status among countries, this relationship weakens when one examines the situation within countries.

If the interest is in increasing the maximum good that health represents in a country, then the standard, aggregate statistics are enough. For example, the average infant mortality in the country gives only part of the picture. We have seen that there has been a steady and welcome decline in infant mortality rates in the Americas, notably over the past four decades. Nevertheless, the gap between the rich and the poor has changed little if at all. I have contended that to some extent that a country is almost a virtual space and that health policy that is consistent with Health for All necessitates data on the distribution of disease mortality and morbidity. We know for instance that there are significant differences in many indicators of mortality and morbidity between rural and urban areas. It is for this reason that PAHO has devoted so much effort in encouraging countries to develop health information systems that can provide data on the health situation in smaller geographical units.

The question is now being put with some seriousness whether the world's health community has lost the enthusiasm for the basic concepts of Health for All and primary health care as espoused in the decade of the 1970s. However, in its most recent examination of the issue, in 1997, the World Health Assembly again ratified the validity of the concept of Health for All and emphasized that equity was the underpinning of the concept. It was pointed out that some of the new challenges that had become more obvious since the Alma-Ata meeting were that more people were living in poverty and that the gaps between the rich and the poor were widening in many countries, communities, and groups. Environmental risks were threatening intergenerational equity, and the rush towards globalization was producing uneven benefits that contributed to intercountry inequities.
In addition, there is questioning of the approach to the control and elimination of specific diseases as being somehow inimical to the basic tenets of Health for All and the fundamental strategy of primary health care. The concern is being expressed that a focus on specific diseases rather than on the basic infrastructure of health services will lead to a distortion in the whole fabric of health systems. Of course, the appropriate answer is that there need not be any conflict, and that the two approaches should be mutually supportive. I have had to come to grips with some of these questions as I have been emphasizing that the concept of equity must be a fundamental value to guide the technical cooperation of PAHO. When I examine the situation in the countries of the Americas and see what is to be done and needs to be done to improve our health status, I am very comfortable with continuing to advocate for the concept of Health for All and the relevance of primary health care as they were enunciated in Alma-Ata as well as for the philosophical and policy aspects of health equity.

Having said that the concepts are relevant in the Americas, let us examine the health situation in Venezuela. When one looks at the traditional indicators of morbidity and mortality, there is no doubt that there has been progress. In the past 60 years there has been an $80 \%$ reduction in the infant mortality rate and a $66 \%$ reduction in the maternal mortality rate. The country shows the health profile typical of most of the middle-income countries of the Americas. The mortality profile shows the predominance of chronic diseases such as cardiovascular diseases and malignancies. But communicable diseases continue to pose problems. In 1998 there were 37586 cases of dengue, and in 2001 this figure was almost double that, reflecting the deficiencies in primary environmental care. While most of the countries of the Western Hemisphere have eliminated measles, it is still occurring in Venezuela, although we suspect that the outbreak was due to an importation from Europe. UNAIDS estimates that there were 62000 persons living with HIV / AIDS at the end of 1999, and, as we have seen elsewhere, the disease is affecting primarily young adults. There is now growing evidence of the disease being transmitted heterosexually. Malnutrition is still a problem, and a quarter of the preschool children attending public school show some evidence of nutritional deficiency. However, I have noted with pleasure that Venezuela has shown a significant decrease in the use of tobacco, thanks to vigorous policies to control it.

But in spite of the progress, there is still much to be done, and one of the major concerns is the distribution of the health problems. Studies done here that looked at the relationship of ill health to the ex- 
tent to which basic needs were unsatisfied showed clearly the disproportionately heavy burden of disease borne by the poor. More poor women are anemic. The measles outbreak appeared in one of the poorest states. When the floods and landslides occurred in 1999, it was the poor who suffered the most. But Venezuela is not unique in this regard. It is a global phenomenon that the poor suffer more ill health, and poverty often prevents them from escaping from the trap into which they fall when illness temporarily deprives them of their earnings. The reduction of poverty has become the numberone social goal of all development efforts.

Much of the response to these health problems undoubtedly must come from the State, and I understand that the Ministry of Health has been restructured to provide much of that response. In 1999 the Ministry of Health and Social Welfare merged with the Ministry of the Family, creating the Ministry of Health and Social Development (MHSD). In its leadership role for the health sector the MHSD is responsible for regulating, formulating, designing, evaluating, controlling, and monitoring the policies, programs, and plans of health and social development; bringing together financing sources and allocating the resources of the National Public Health System; providing comprehensive health service to all the sectors of the population, especially those who are low-income; and promoting citizen participation.

But the actions of the MHSD have to take place in the context of the political climate. As in every country the practice of health in Venezuela must bear some relation to the place that health has in the fundamental principles espoused by the body politic. I therefore examined Venezuela's new Constitution to see what it said about health, and whether there were any changes envisioned in the policies of the health sector as a whole.

Let me cite Article 83 of the new Constitution:

Health is a fundamental social right and an obligation of the State, which will guarantee it as a part of the right to life. The State will promote and develop policies aimed at improving the quality of life, collective well-being, and access to services. All people have the right to health protection as well as the duty to participate actively in promoting and defending it and to comply with the sanitary measures established under law, in accordance with the treaties and international agreements signed and ratified by the Republic.

One could not wish a clearer statement of the importance of health. This incorporates the principles of universality and also speaks to the impor- tance of social participation, which is a necessary complement to making individuals responsible for those aspects of health that lie within their peculiar competence. It means that the State, and in this case the MHSD, will have to assume the role of guiding and leading, which is an essential aspect of the reform of health services. This vital aspect is often forgotten, but it is expressed clearly in Article 84 of the Constitution:

In order to guarantee the right to health, the State will create, exercise a leadership role for, and manage a national public health system that is intersectorial, decentralized, and participatory; that is integrated into the Social Security system; and that is governed by principles of free services, universality, comprehensiveness, equity, social integration, and unity.

Further on, Article 86 of the Constitution indicates that all persons, whether or not they are contributors, have the right to Social Security, including health care.

We can thus see that the Constitution enshrines the notion of equity in terms of the factors that determine health outcomes. The Constitution is also framed exactly in the kind of language and embraces the basic philosophical principles of Health for All. I wish to believe that this concern for equity in terms of health is a reflection of a concern for a more just and equitable society in general. Equity in health cannot be seen as apart from equity in the other spaces or dimensions of human development. The view has been put forth by Amartya Sen and others that we should think of development as the process of expanding both freedoms and capabilities; progress in one enhances the other.

These concepts of equality are not new to Venezuela or Venezuelans. In 1815 the great patriot Simón Bolívar, in his famous "Letter from Jamaica," railed against the indignities of colonial servility and evoked some of the noble sentiments that have persisted in the Americas to this day. In one part of the letter he wrote:

South Americans have made efforts to obtain liberal, even perfect, institutions, doubtless out of that instinct to aspire to the greatest possible happiness, that, common to all men, is bound to follow in civil societies founded on the principles of justice, liberty, and equality.

I would hope that these sentiments are as alive today as they were in 1815 .

I thank you for your attention. 